\title{
Alicia D’Amico. Exploraciones sobre el deseo lésbico a través de la fotografía
}

\author{
María Laura Rosa ${ }^{1}$
}

Recibido: 30 de enero de 2018 / Aceptado: 15 de mayo de 2018

Resumen. La fotógrafa Alicia D’Amico (Buenos Aires, Argentina, 1933-2001) fue una importante activista feminista, involucrada con los movimientos de mujeres de la segunda ola argentina. Entre finales de los años 80 y principios de los 90 del siglo XX, desarrolló una serie fotográfica en la que reflexionó sobre la identidad femenina, y en particular, sobre la construcción del deseo lésbico. $\mathrm{Su}$ investigación es de radical originalidad en el panorama de la fotografía argentina.

Palabras clave: Fotografía argentina; Arte feminista; Lesbianismo

\section{[en] Alicia D'Amico Explorations on lesbian desire through photography}

\begin{abstract}
The photographer Alicia D'Amico (Buenos Aires, Argentina, 1933-2001) was an important feminist activist, involved in the women's movements of the Argentinian second wave. Between the end of the 80 s and the beginning of the 90 s of the 20th century, she developed a photographic series in which she reflected on female identity, and in particular, on the construction of lesbian desire. Her research is of radical originality in the outlook of Argentine photography.
\end{abstract}

Keywords: Argentine photography; feminist art; Lesbianism.

Sumario. 1. Breve historia de la segunda ola feminista en Buenos Aires. 2. La cuestión de las imágenes femeninas: de la mujer verdad a la autoexploración del deseo. 3. Bucear en el deseo lésbico. 4. Conclusiones.

Cómo citar: Rosa, M. L. (2018) Alicia D’Amico. Exploraciones sobre el deseo lésbico a través de la fotografía, en Anales de Historia del Arte n ${ }^{\circ} 28$ (2018), 297-314.

\section{Breve historia de la segunda ola feminista en Buenos Aires}

En 1969, se organizó en los salones del café Tortoni la Unión Feminista Argentina (UFA), de cuyos orígenes participaron la cineasta María Luisa Bemberg, la fotógrafa Alicia D’Amico, la escritora Leonor Calvera, la especialista en teatro Marta Migueles y la poeta y escritora Hilda Rais, entre otras mujeres, en su mayoría de clase media. En 1971, se conformó también el Movimiento de Liberación Femenina (MLF) que instaló con fuerza el debate sobre el aborto. Dichas agrupaciones realizaron

1 Consejo Superior de Investigaciones Científicas y Técnicas (CONICET)

Instituto Interdisciplinario de Estudios de Género (Universidad de Buenos Aires)

marialaurarosa@hotmail.com

Código ORCID: 0000-0003-1748-3179 
reuniones de concienciación y grupos de estudio y discusión de textos feministas. En ese sentido, fue fundamental el ensayo de Simone de Beauvoir El segundo sexo, el cual había sido editado en Buenos Aires en 1954 por la editorial Psique, con traducción de Pablo Palant ${ }^{2}$. También fueron discutidas autoras extranjeras traducidas por estas mujeres, como ser: Carla Lonzi, Shulamith Firestone y Kate Millet, entre otras. A estas actividades se sumó el activismo callejero, realizando volantes para ser entregados en la vía pública.

Una de las primeras cuestiones que las feministas expusieron críticamente fue el modelo del ama de casa. Éstas visibilizaron el trabajo agotador, no remunerado y depreciado de las labores domésticas, exigiendo que sea asalariado. Un temprano volante $^{3}$ de UFA para el día de la madre 4 de 1970, exhibía a una mujer preparando la comida frenéticamente, mientras atendía el teléfono con sus pies y se ocupaba de los tres niños que intentaban hacer destrozos frente a la ropa lavada que ella recién terminaba de colgar. A su lado, en una mesa, la TV transmitía un aviso que la incitaba a mostrarse hermosa, gracias al uso de la loción Sexy. En la parte inferior del dibujo, un epígrafe señalaba: "Madre: esclava o reina, pero nunca una persona".

En este sentido, la figura de María Luisa Bemberg se destacó con fuerza. Ella fue una de las primeras creadoras que relacionó los reclamos feministas con su producción fílmica dado que las integrantes de UFA instaron a Bemberg a emplear la cámara para denunciar eventos de carácter sexista. Las demandas de UFA sobre el "(...) esclarecimiento teórico de cómo funciona el aparato de opresión de la mujer y la denuncia de toda idea, sentimiento o conducta que mantenga o refuerce tal opresión (...)", así como también la "(...) revisión de libros de textos, y todo sistema de educación para eliminar la discriminación condicionante de los roles sexistas, desde el jardín de infantes (...)"6, fueron los fundamentos de los cortos de Bemberg pensados y realizados entre 1972 y 1978: El mundo de la mujer y Juguetes, respectivamente?

Durante los años 60 y 70 la Argentina vivió un momento de renovación y expansión de los mass-media, los que dejaron de ser canales de comunicación y circulación de la información para transformarse en fuertes agitadores del consumo, empleando en numerosas ocasiones al cuerpo femenino para la venta de cualquier producto. Esto impactó sobre las mujeres del momento, ya que rápidamente devinieron en blancos de la publicidad a través de la televisión y de numerosas publi-

2 Ver: Nari, M. (2013). No se nace feminista, se llega a serlo. Lecturas y recuerdos de Simone de Beauvoir en la Argentina, 1950 y 1990. En P. Halperin, y O. Acha (Eds.): Cuerpos, género e identidades. Estudios de historias de género en Argentina. Buenos Aires: Ediciones del siglo, 291-307.

3 El citado volante fue costeado por la cineasta María Luisa Bemberg. Ella se lo habría encargado a un publicista para que lo diseñara, el folleto formó parte de la campaña realizada por UFA para denunciar la explotación de las mujeres. Ver Vassallo, A. (2005). Las mujeres dicen basta: movilización, política y orígenes del feminismo argentino en los '70. En A. Andújar, D. D’Antonio, K. Gramático, F. Gil Lozano, A. Vasallo, Historia, género y política en los '70, Buenos Aires: Feminaria, 61-88.

4 En Argentina se celebra el Día de la Madre desde principios del siglo XX. Dicha celebración fue diversa por la creciente inmigración, pero hacia los años ‘40 la iglesia vinculó la figura de la madre con la de la virgen María. Es así como el Día de la Madre, primero estuvo ligado a lo religioso, y recién a finales del siglo XX, comenzó a ceder la fuerte diferencia entre el 11 de Octubre 'Día de la madre católica', de otros días. Con el tiempo -debido al impulso comercial que cobra el festejo y por el rechazo popular a la idea de separar a las madres católicas de todas las demás- fue consolidándose el tercer domingo de Octubre como el Día de la Madre Universal.

Folleto de Unión Feminista Argentina, 1970.

Inquietud de entidades locales por la urgente emancipación femenina. La Opinión. 26 de agosto de 1973.

Para un desarrollo exhaustivo de los cortos de María Luisa Bemberg, ver: Rosa, M. L. (2014). Legados de libertad. El arte feminista en la efervescencia democrática. Buenos Aires: Biblos, 21-45. 
caciones femeninas que, en el apogeo que vivía por entonces el mercado editorial, circulaban ampliamente. En este complejo entramado consumista, aparecieron voces femeninas que rechazaban el modelo sexista y cosificado del mercado. Es así como Catalina Trebisacce señala que:

Las feministas locales de la primera mitad de la década del setenta se desidentificaron de los estereotipos de mujeres pasivas y hogareñas, y también lo hicieron del ideal cos(it)a-bella. Finalmente, también se extrañaron del imperativo de la maternidad como fundante de la identidad de toda mujer ${ }^{8}$.

Aunque durante varios años se sostuvo que las feministas argentinas no se sintieron integradas en las agrupaciones de izquierda y que por ello se distanciaron de las mismas conformando las propias, en los últimos años surgieron investigaciones que iluminaron, revisaron y cuestionaron este supuesto ${ }^{9}$. Las relaciones entre los grupos de izquierda con los movimientos de mujeres fueron ambiguas debido a que en los primeros, sus integrantes también discutieron problemáticas vinculadas con el sistema de desigualdad que imperaba entre los géneros y, por esta razón, establecieron vínculos con las feministas. Así señala Eva Rodríguez Agüero:

Si bien la idea de que la liberalización de las costumbres privadas buscaba seguir un modelo impuesto por las sociedades imperialistas [la izquierda de los 70 sostenía que la ideología feminista era importada de estos países desarrollados, principalmente Estados Unidos, omitiendo la genealogía histórica de los feminismos locales] atentó contra el establecimiento de puentes entre las luchas feministas y otras experiencias políticas, existieron algunos intentos de tender lazos entre mujeres feministas y mujeres políticas. Una de ellas fue la formación del Frente de Lucha por la Mujer, que aglutinaba a feministas y mujeres de partidos políticos de izquierda ${ }^{10}$.

Aunque el desarrollo alcanzado por los grupos feministas de Buenos Aires durante la primera mitad de la década del 70 se vio afectado por el golpe militar del 24 de marzo de 1976, hacia 1982 se reorganizaron estas agrupaciones a través de las actividades que planificó DIMA (Derechos Iguales para la Mujer Argentina) ${ }^{11}$. Una de ellas fue el Primer Congreso Argentino La Mujer en el Mundo de Hoy-25 y 26 de octubre de 1982-. Al año siguiente se realizaron las Jornadas de la Creatividad Femenina -1, 2 y 3 de abril de 1983-, cuyo lema fue 'En toda mujer hay una creadora y en toda creadora hay una mujer'. Finalmente, en el mes de mayo de ese mismo año, se realizó el Segundo Congreso La Mujer en el Mundo Hoy.

8 Trebisacce, C. (2013). Memorias del feminismo de la ciudad de Buenos Aires en la primera mitad de la década del setenta. Buenos Aires: Facultad de Filosofía y Letras. Universidad de Buenos Aires.

9 Trebisacce, C. (2013) Encuentros y desencuentros entre la militancia de izquierda y el feminismo en la Argentina. Revista Estudios Feministas, vol. 21 (2), 439-462

10 Rodríguez Agüero, E. (2013). Feminismos del Sur. Mujeres política y cultura en la Argentina de los ’70. Málaga: Atenea/Universidad de Málaga, 149.

11 Es importante destacar que en el año 1982 Leonor Calvera publica su libro El género mujer, en donde por primera vez se desarrolla el concepto de género en Argentina. Calvera, L. (1982). El género mujer, Buenos Aires: Editorial de Belgrano. 
En agosto de1983 - unos meses antes del regreso democrático con la presidencia de Raúl Alfonsín- se creó Lugar de Mujer, en donde se recibieron a todas aquellas que deseaban acercarse, más allá de la autodesignación feminista. En dicho espacio se realizaron actividades, talleres, exposiciones artísticas, proyección de cine, grupos de estudio, entre otros eventos. Algunas de sus fundadoras fueron: Marta Migueles, Hilda Rais, María Luisa Lerer, María Luisa Bemberg, Sara Torres, Graciela Sikos, Lidia Marticorena, Ana Amado, Elizabeth Jelin y Alicia D’Amico. Allí se produjo un juego de ida y vuelta entre el campo artístico local y el activismo feminista ya que las artistas, tales como Teresa Volco, Ilse Fusková, Josefina Quesada, o la misma Alicia D’Amico, llevaron problemáticas y debates que se enriquecieron con discusiones y propuestas, hecho que trajo como consecuencia un momento dorado del arte feminista argentino ${ }^{12}$.

Finalmente, a partir de diciembre de 1983 con la restauración de la democracia y la consiguiente libertad de expresión, el trabajo feminista emergió con fuerza. Las reivindicaciones cobraron un nuevo impulso gracias al retorno de las mujeres exiliadas, la incorporación de mujeres de agrupaciones políticas partidarias ${ }^{13} \mathrm{y}$ el acercamiento de jovencitas, entre otros factores. El campo artístico no fue ajeno a esta situación, dado que las creadoras recobraron su participación activa en el medio, comenzando a exponer problemas propios del género.

Nos detendremos en analizar una serie de trabajos fotográficos de Alicia D'Amico (Buenos Aires 1933-2001), quien fuera una de las más importantes fotógrafas argentinas del siglo XX, fundadora del Consejo Argentino de Fotografía y cofundadora junto a Cristina Orive y a Sara Facio de la editorial La Azotea, pionera en fotolibros latinoamericanos. Fue ampliamente reconocida por sus retratos a destacados escritores -como ser Alejandra Pizarnik, Olga Orozco, Pablo Neruda, Jorge Luis Borges, Julio Cortázar- y por su series publicadas en libros, especialmente Buenos Aires, Buenos Aires (1968), Humanario (1977), Podría ser yo. Los sectores urbanos en imágenes y palabras (1987), entre otros. Sin embargo, su implicancia con los movimientos de mujeres y su compromiso con el activismo feminista, que la llevó a importantes trabajos de investigación y documentación fotográfica, fueron escasamente exhibidos en vida de la fotógrafa y, tras su muerte, quedaron en el olvido.

\section{La cuestión de las imágenes femeninas: de la mujer verdad a la autoexploración del deseo}

Hacia 1982, en coincidencia con las primeras jornadas de DIMA, Alicia D'Amico se embarcó en la investigación Creación de la propia imagen, en la que trabajó hasta el final de su vida, vale decir, hasta el año 2001. Buscó representar, a través del género del retrato fotográfico, imágenes de mujeres que reflejaran cómo se autopercibían.

12 Para un desarrollo de este período ver: Rosa, M. L. (2014). Legados de libertad. El arte feminista en la efervescencia democrática. Buenos Aires: Biblos.

13 Ver: Trebisacce, C.: Un análisis de las narrativas construidas por las feministas de ATEM 25 de noviembre, en los ochenta, sobre el feminismo local precedente. II Jornadas del Centro Interdisciplinario de Investigaciones de Género, Facultad de Humanidades y Ciencias de la Educación, Universidad de La Plata. En Memoria Académica. La Plata: Universidad de La Plata, 40-48. Obtenido de: http: //www.memoria.fahce.unlp.edu.ar/ trab_eventos/ev.4898/ev.4898.pdf

Asimismo ver, Rodríguez Agüero, E. (2013). Feminismos del Sur. Mujeres politica y cultura en la Argentina de los '70, ob. cit. 
Para ello desarrolló una serie de talleres junto a psicólogas en donde, tras la conformación de un grupo de mujeres convocadas para trabajar un determinado tema, el resultado final fueran retratos de cada una de las participantes. Esta modalidad se llevó a cabo particularmente en Lugar de Mujer, en los Encuentros Feministas Latinoamericano y del Caribe y en los Encuentros de Lesbianas Feministas de América Latina y el Caribe, entre otros espacios de militancia feminista y lesbofeminista.

Involucrada en esta pesquisa, hacia mediados de los años 80, comenzó a preguntarse por la representación del deseo lésbico, hecho que la llevó a fotografiar parejas con el fin de capturar su manifestación. Sin embargo, esto también implicó un acto político: la visibilidad del colectivo lésbico en un país en el que la homosexualidad -tanto femenina como masculina-implicaba cargar con un lastre, como ya veremos. Durante los años 90, la fotógrafa estuvo involucrada en esta cuestión, tornando a la fotografía en una herramienta de reflexión sobre la identidad. En este apartado nos detendremos brevemente en lo que hemos esbozado, con el fin de contextualizar la serie dedicada a las parejas lesbianas que veremos más adelante.

Como comentamos, en 1982 Alicia D’Amico inició su investigación Creación de la propia imagen, en la que a través del retrato fotográfico buscó desarticular el entramado visual que cristalizaba a la mujer en mandatos sociales, domésticos, de belleza, etc. En el Primer Congreso Argentino La Mujer en el Mundo de Hoy, D'Amico invitaba a posar a las mujeres que se acercaban. Su método era muy sencillo, así expresó:

Realicé una serie de retratos de participantes de un congreso feminista, con cámara $35 \mathrm{~mm}$., luz natural proveniente de una ventana únicamente y encuadré sistemáticamente de frente. En las fotos sólo cambian las modelos y sus expresiones, su forma de "dar la cara" a la cámara. El concepto de belleza elegido fue el de reflejar la energía profunda y la sensibilidad que transmite cada persona. La verdad que cada una pone en evidencia más allá de los refinamientos técnicos adecuados para tomar distintas posiciones ${ }^{14}$.

El concepto mujer verdad fue desarrollado a lo largo de sus trabajos, entendiendo por ello a las fotografías que reflejaran fielmente los deseos, elecciones personales y todo aquello que sentía como característico de las retratadas. Por este motivo, este concepto puede vincularse con el de mujer nueva, enunciado por las miembras de UFA y el cual creemos que se encuentra en el origen de la noción de D'Amico. Dicha categoría fue empleada para nombrar a aquellas mujeres que habían cobrado conciencia de su opresión dentro del sistema patriarcal, y por tanto, buscaban ser protagonistas de sus propias vidas, peleando por la igualdad de sus derechos. Así indicaba el Manifiesto de la UFA:

[La mujer nueva es] mentalmente joven, vital, lúcida y decidida. (...) La MUJER NUEVA no admite seguir siendo una eterna menor de edad, y dice BASTA A LAS DIFERENCIAS. La discriminación sexual y salarial, la marginación política, la

14 D’Amico, A. (1984). Salud, identidad y socialización. Relaciones con la imagen fotográfica. En V.V.A.A. (1984) ;Es preciso volar! Primer encuentro regional sobre la salud de la mujer. Bogotá: Edición de la Mujer, 55 . 
patria potestad, la subordinación económica, la dependencia marital, los quehaceres domésticos no remunerados, la esclavitud de estos quehaceres no compartidos con el varón sumados a un trabajo fuera del hogar, el embarazo no deseado, la erotización comercializada de la mujer, una moral diferente para cada sexo. Estas son alguna de las notorias diferencias. Mientras subsistan es imposible que la mujer se considere y sea considerada un ser humano completo. Nos han hechos rivales. Nosotras nos descubrimos hermanas. Hacemos un llamado a todas las mujeres sin discriminación social, política, cultural o generacional para que se solidaricen con este movimiento que tiene como primer objetivo crear una conciencia NUEVA ${ }^{15}$.

Para D’Amico la mujer nueva, quien buscaba la igualdad ciudadana y peleaba por sus libertades, completaría su liberación cuando las imágenes dieran cuenta de ello. Es decir, su subjetividad y su agenciamiento debían tener un correlato en una representación visual. Así escribió en 1984:

La identidad no se recibe ni se regala. Es producto de un trabajo sistemático con una misma, nacida de la voluntad de ser sujeto y no objeto. La identidad debe ser asociada con la creatividad y la creatividad tiene relación directa con la libertad. La creatividad es jugar con las posibilidades de ser, de juzgar, de elegir. Las mujeres tenemos características propias que no son necesariamente las que nos dicen que tenemos. (...) Tenemos que aprender a mirar desde nosotras mismas. (...) La fotografía es un elemento indispensable, diría yo, para definirnos y ejemplificar nuestra inserción en el mundo. Sobre todo, es un elemento fundamental para nuestro proceso de identidad ${ }^{16}$.

Al enfrentar a las mujeres ante su propia imagen, D'Amico cuestionó la heterodesignación, entendiendo por ello la delimitación de la identidad impuesta desde el exterior hacia el sujeto. Asimismo profundizó en este género, ampliando sus límites y explorando otras metodologías para abordarlo. Lo utilizó como una herramienta feminista para que las mujeres pudieran reflexionar sobre su identidad.

Si bien en el ámbito internacional, la teoría del arte feminista-que se fue conformando junto a los movimientos de mujeres de la década del 70-, ya había comenzado a plantear críticamente el lugar que ocupaba la mujer en la representación del arte occidental; en Argentina, las más tempranas manifestaciones teóricas las encontramos en artistas que, como militantes de las agrupaciones, reflexionaron sobre ello en entrevistas, textos personales y en las propias obras. Las figuras más relevantes fueron María Luisa Bemberg y Alicia D’Amico, aunque no descartamos que en futuras investigaciones surjan más voces.

Aunque la fotógrafa inició su investigación en 1982, con anterioridad a esta fecha había formado parte del comité editorial de la revista feminista Persona ${ }^{17}$, en donde participó de

15 Manifiesto de la Unión Feminista Argentina. Luchas por la reivindicación de las mujeres. La Opinión. 23 de abril de 1972. s.p.

16 D’Amico, A. (1984). Salud, identidad y socialización. Relaciones con la imagen fotográfica. En V.V.A.A. (1984) ;Es preciso volar! Primer encuentro regional sobre la salud de la mujer Bogotá: Edición de la Mujer, 51-55.

17 Persona, fue una revista feminista pionera para su época. Su creación tiene lugar en el seno del Movimiento de Liberación Feminista (MLF), fundado en 1972, por la militante María Elena Odonne. Tuvo dos momentos, uno 
la selección y publicación de notas sumamente críticas a la cosificación femenina en los mass-media, las que varias de ellas empleaban fotografias de su archivo personal ${ }^{18}$.Con lo cual podemos advertir que las lecturas y reflexiones de los grupos feministas fueron creando la necesidad de nuevas representaciones visuales. Si en los años 70 las mujeres redescubrían sus cuerpos, comenzaban a permitirse el goce sexual -uno de los temas más debatidos fue el del orgasmo femenino ${ }^{19}-$, y se daban cuenta de que se encontraban enajenadas en las imágenes que circulaban sobre el género; en los años 80 se tornó urgente que la mujer nueva tuviera un correlato visual, así surgió la mujer verdad. Comentaba D'Amico:

El cómo somos estuvo siempre definido por el cómo nos ven. Al decirnos cómo nos ven, nos dicen simultáneamente cómo debemos ser.

Llegó el tiempo de pensarnos, de preguntarnos ¿Cómo somos las mujeres? ¿Cómo nos vemos? Luchamos por la igualdad social, pero, no queremos perder las diferencias que nos distinguen del otro sexo. Si somos diferentes, tenemos que mirarnos en forma diferente. Si existe una mirada femenina, ésta puede ser trasladada fotográficamente ${ }^{20}$.

Partiendo de la idea enunciada por Roland Barthes en su libro La cámara lúcida (1980), es decir, que la fotografía es un certificado de presencia, lo cual diferenciaba a este arte de las demás, para D'Amico este hecho la vinculaba con la técnica que mejor podía reflejar las construcciones de la identidad a través de la representación visual. La fotografía habilitaba a ello, y al hacerlo, se tornaba poderosamente política, entendiendo este concepto desde el punto de vista feminista: lo personal es político. La metodología delimitaba un recorrido que iba desde la subjetividad a la imagen, fruto del trabajo en grupo, de la interacción entre la retratada con la fotógrafa y de ésta con su representación. Para ello empleaba técnicas vinculadas con la psicología y el psicodrama, así como también, el teatro. Los momentos de confrontación con los trabajos eran ricos e intensos, se discutía qué era lo que sentía cada una de las mujeres al verse, sus palabras quedaban registradas y acompañaban a las piezas. La experiencia que se daba frente a la autopercepción formaba parte de la obra.

Una de las primeras veces que D'Amico llevó a cabo esta metodología de trabajo fue en el taller Autorretrato, dictado junto a la psicóloga Graciela Sikos en Lugar de Mujer. Parte del material resultante fue publicado en el periódico Alfonsina ${ }^{21}$, en el artículo Cómo Somos, firmado por la misma fotógrafa. Allí explicaba:

durante los años 70, cuando se publican seis números entre 1974 y 1975 . Otro durante los años 80 , con trece números entre 1980 y 1983.

18 Ejemplo de ello es la entrevista que le realizan a la ex Miss Argentina y actriz Isabel Sarli. Las fotos fueron tomadas por D’Amico. Ver: Sin Autor (1975). Concurso de belleza. Persona, 4, 31-34.

19 Al respecto señaló la feminista Marta Miguélez: "Las feministas de los 70 descubríamos la opresión, pero la descubríamos en pelea, la descubríamos en acción y la descubríamos en reivindicaciones del principio del placer, creo que el eje para mí más atractivo del feminismo siempre fue que cómo lucha política implicaba deber, divertirnos o bailar entre nosotras, pasarlo muy bien, descubrir nuestros cuerpos, masturbarnos hasta lograr la mayor cantidad de orgasmos que pudiéramos e ir dándonos cuenta que nuestro centro orgásmico -el clítoris-, había sido negado por la cultura, y que nosotras lo reivindicábamos y que era bueno estar con nosotras mismas, con nuestros propios cuerpos, era parte de esta cosa del descubrimiento de todo lo que hacía nosotras." En Coloquio feminista de los '70, 2002, grabación.

20 D’Amico, A. (1984). Salud, identidad y socialización. Relaciones con la imagen fotográfica. En V.V.A.A. (1984) iEs preciso volar! Primer encuentro regional sobre la salud de la mujer. Bogotá: Edición de la Mujer, 53.

21 Publicación que reflejó las discusiones feministas y su impacto en la realidad política, había comenzado a circular en diciembre de 1983. 
La hipótesis de trabajo sostiene que existe una mirada fotográfica femenina capaz de crear una nueva estética, redefiniendo el concepto tradicional de belleza; mirando de manera diferente, juzgando y creando de manera diferente. La mujer puede transformar la imagen de la mujer. (...) La identidad femenina pasa ahora a ser una cuestión de las mujeres ${ }^{22}$.

Sin ánimo de promover una lectura esencialista y/o de plantear argumentos que nos conducirían al binomio mujer/naturaleza -temáticas en las que no creo que la fotógrafa estuviera interesada-, D'Amico se propuso investigar cómo la libertad sobre el propio deseo y el cuerpo femeninos podía crear otras imágenes de mujeres, diferentes de las que por entonces circulaban masivamente a través de los medios de comunicación. Los géneros del retrato y el desnudo se acoplaron. La fotógrafa estudió con la lente a sus retratadas hasta alcanzar la autenticidad buscada en las imágenes finales. La intimidad se tornó sinónimo de honestidad en sus fotografías.
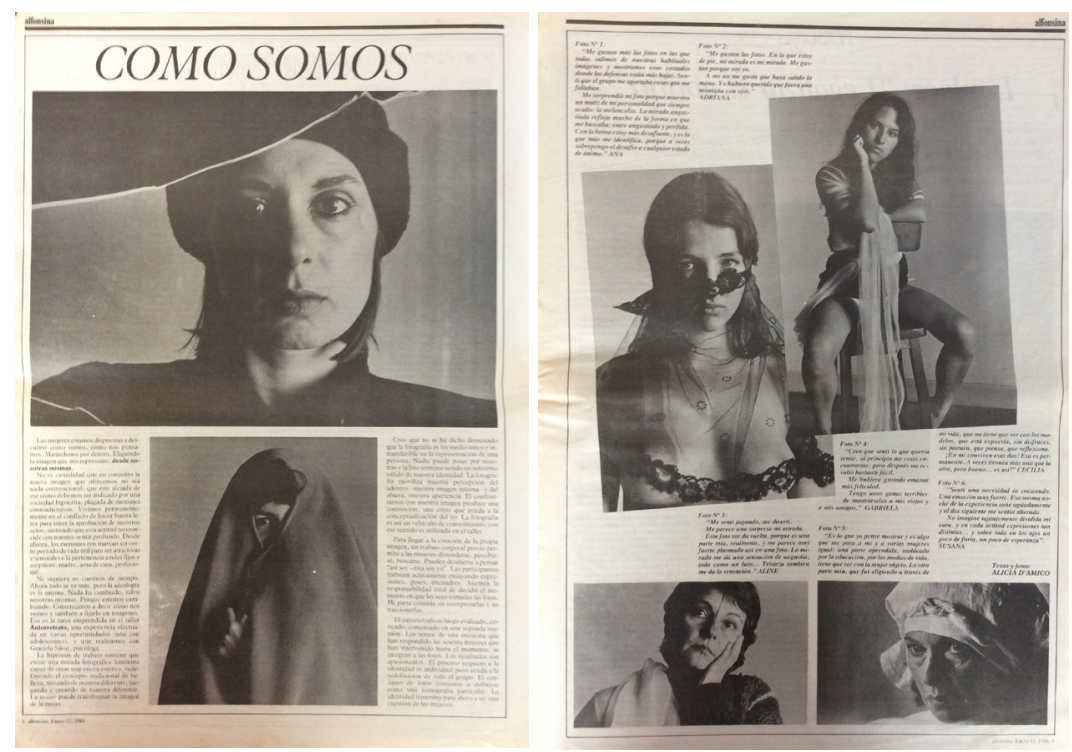

1. Alicia D’Amico, Cómo Somos en alfonsina, 1984, pp.8-9. Archivo María Laura Rosa

El ejercicio de pensarse a sí mismas a través de la fotografía, nos lleva a destacar ciertas particularidades del contexto argentino durante los años 80 . Junto a la salida de un régimen dictatorial genocida, con secuelas graves para los derechos humanos y los vínculos sociales, coincidieron la madurez alcanzada por los feminismos locales, la llegada de mujeres exiliadas que venían con información fresca sobre los feminismos extranjeros y la necesidad genuina de socialización, de recuperación de la comunicación física y afectiva entre las mujeres. Los comentarios de las integrantes de Autorretrato reflejaron estas características del entorno. Es el caso de Ana:

22 D’Amico, A. (1984). Cómo Somos. alfonsina, 3, 8. 
Me gustan más las fotos en las que todas salimos de nuestras habituales imágenes y mostramos esos costados en donde las defensas están más bajas. Sentí que el grupo me aportaba cosas que me faltaban. Me sorprendió mi foto porque muestra un matiz de mi personalidad siempre oculto: la melancolía. La mirada angustiada refleja mucho de la forma en que me buscaba; entre angustiada y perdida. Con la boina estoy más desafiante, y es la que más me identifica, porque a veces sobrepongo el desafío a cualquier estado de ánimo. ANA $^{23}$

Ana era la profesora e intelectual Ana Amado (Santiago del Estero 1946-Buenos Aires 2016 ${ }^{24}$ quien había regresado recientemente al país, tras el exilio junto a su marido, Nicolás Casullo, primero en Caracas (1974-1975) y luego en México (19761983). Ella perteneció a esas mujeres curiosas e informadas que ansiaban insertarse en el clima de apertura cultural, vivido por entonces en la ciudad de Buenos Aires. La imagen reflejaba la melancolía en la mirada, tal como apuntaba la retratada, quizás por la experiencia nómade del exilio. La angustia sentida por cómo reconstruir su vida en una Argentina que buscaba revivir sin olvidar el pasado, fue algo característico de muchas/os exiliadas/os de aquellos años. En este contexto, algunas mujeres consideraron que era imprescindible pensar en cómo querían verse y ser vistas, cómo querían nombrarse y ser nombradas. Había esperanzas de cambio y ellas se sentían protagonistas de la historia. El corte fortuito realizado por la cámara al enrollar la película, fue preservado por la fotógrafa como parte de la obra, y sin lugar a dudas, generó un marco misterioso para el rostro de Ana.

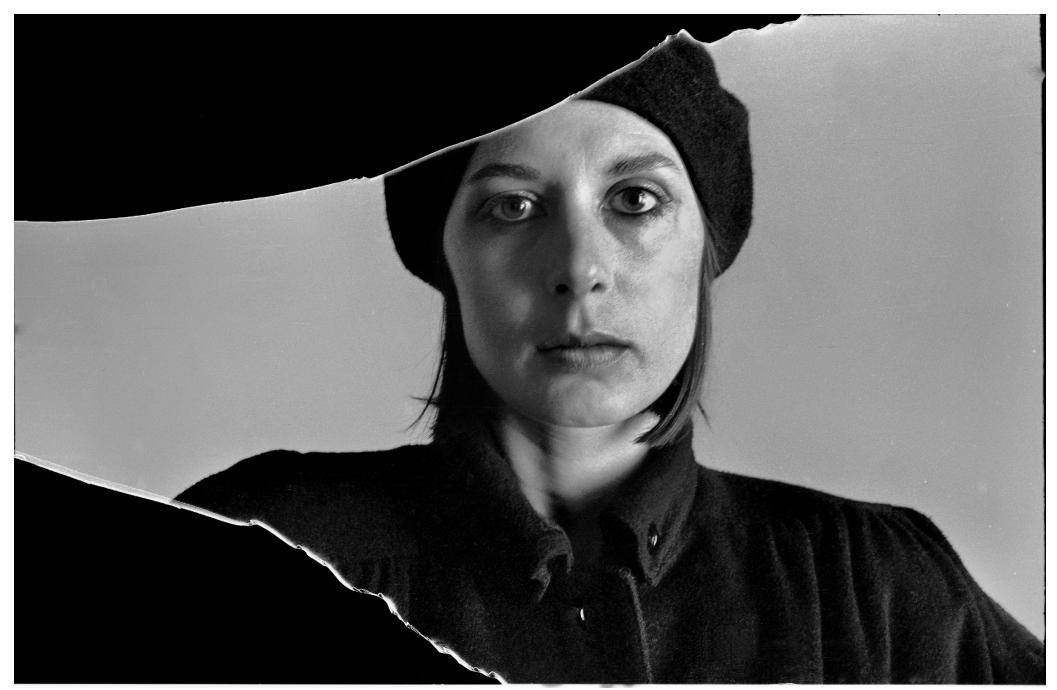

1.1. Alicia D'Amico, taller Autorretrato, 1984. (Retrato de Ana Amado) Copia de escaneos de negativo original, reproducción de contactos de negativo original, $35 \mathrm{~mm}$. Archivo Alicia D’Amico.

23 D’Amico, A. (1984). Cómo Somos. alfonsina, 3, 9

24 Ana Amado fue corresponsal en Argentina de Fempress, Red Alternativa de Prensa Feminista para América Latina desde 1983 a 2001. 
Mientras los talleres se iban repitiendo, y avanzaban los años 80, el encuentro entre la psicóloga Liliana Mizrahi con Alicia D’Amico generó una búsqueda diferente: desde la subjetividad femenina, la investigación dio un giro hacia la exploración sobre la circulación del deseo entre las mujeres. Pies desnudos, iniciada en 1985, fue una de las primeras series que dio cuenta de ello, la componen veintiséis fotografías. La misma se inició gracias al pedido de la escritora Diana Bellessi de una imagen para la tapa de un libro de poemas de su autoría, pronto a ser publicado ${ }^{25}$.

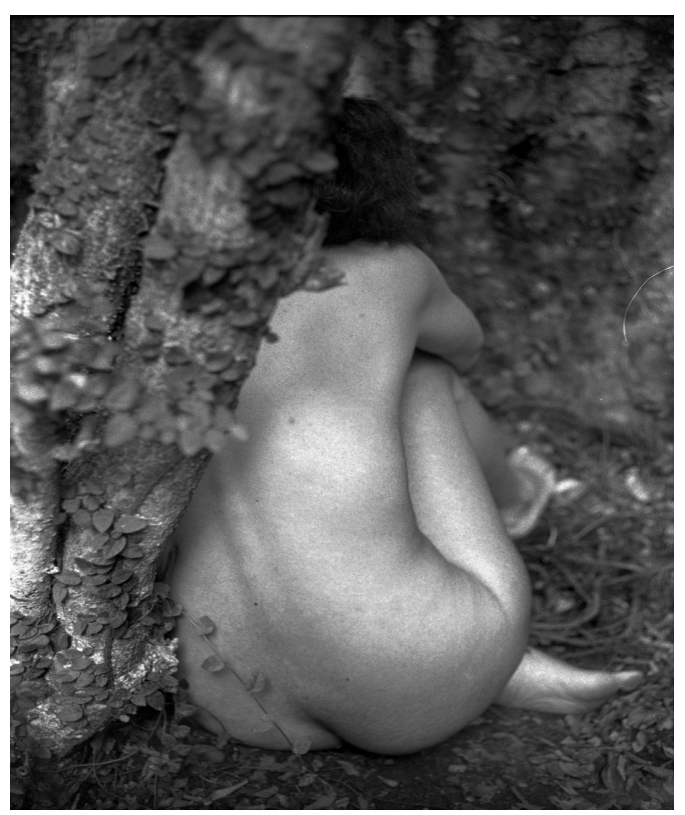

2. Alicia D’Amico, fotografía, Liliana Mizrahi, performance, Pies desnudos, 1985. Copia de escaneos de negativo original, reproducción de contactos de negativo original, $35 \mathrm{~mm}$. Archivo Alicia D'Amico.

Liliana Mizrahi iba interactuando con la naturaleza del jardín de su casa. Buscaba mimetizarse con la vegetación, se movía entre las ramas y los frutos de los árboles, adoptaba diferentes personajes imaginarios. Su gato la acompañaba. La mirada de D'amico se posaba en distintas zonas de su torso, la luz iba dejándose absorber por las plantas y reflejándose en el cuerpo femenino, tornando a la piel en seda.

A mediados de los años 80, el género del desnudo fotográfico le permitió a Alicia D'Amico crear un repertorio visual que exponía nuevas investigaciones sobre identidades y deseos históricamente invisibilizados. Así indicaba Liliana Mizrahi: "Buscamos reconocer el deseo, señalarlo y legitimarlo como lo que es: un deseo legítimo"26. Pies desnudos fue un ejercicio fotoperformático a medio camino entre la autoconfesión y la autoexploración de la propia mirada de la fotógrafa ante su amante. Al retratar a su enamorada, se desnudaba a sí misma. 


\section{Bucear en el deseo lésbico}

Si bien, a nivel internacional, la temática lésbica ingresó al campo artístico durante el siglo XIX, lo hizo ocupando un lugar marginal tanto en el orden discursivo de la disciplina como en el de la práctica artística. A partir de los años 70 del siglo XX, esta situación comenzó a cambiar dado que emergieron voces que, desde los movimientos feministas, reclamaron derechos para el colectivo lésbico. Señala Laura Cottingham:

No es sorprendente que la historia del lesbianismo haya emergido en los estudios académicos sólo recién en 1970, después de que las lesbianas, aparentemente por primera vez en la historia, se asumieran como grupo y, por tanto, como gente que podía tener una historia propia ${ }^{27}$.

Es importante destacar que en los Estados Unidos, en 1977, de la mano de la historiadora del arte estadounidense Arlene Raven (Estados Unidos, 1944-2006), se conformó el Lesbian Art Project (LAP), colectivo que se dedicó tanto a la creación como a la investigación sobre artistas lesbianas e historia del arte. Por entonces, las creadoras reflexionaron sobre las particularidades del deseo lésbico a través del performance. También llevaron a cabo la pieza de teatro experimental Femina: An IntraSpace Voyage (1978), entre otras obras. Al respecto, Terry Wolverton señaló:

En una temprana reunión de LAP, Arlene había observado que, como colectivo, nosotras necesitábamos emplear nuestras propias vidas como material de investigación, nuestras propias experiencias como lesbianas para la conformación de nuestra teoría. Nosotras aceptamos la premisa ya que estábamos bien entrenadas en que 'lo personal es político'28.

El concepto de experiencia, el cual comenzó a cobrar un valor político dentro de los grupos de concienciación de los feminismos de los 70, pronto se manifestó como una herramienta metodológica que daba la posibilidad de construir otras interpretaciones y relatos dentro de las disciplinas académicas, sin por ello dejar de generar intensas polémicas ${ }^{29}$.Sin ánimo de detenerme en las discusiones que motivó este concepto en el campo metodológico y epistemológico feminista, sí tomaremos la interpretación de Teresa de Lauretis dado que la consideramos iluminadora de nuestra investigación. También la autora se manifiesta ante el concepto de subjetividad y de identidad que pueden ser de igual utilidad para la interpretación de las fotografías de D’Amico. Así indica:

Por experiencia no me refiero a lo que uno sabe o puede hacer bien, sino también al conjunto de hábitos, disposiciones, recuerdos, actitudes y expectativas que cada

\footnotetext{
27 Cottingham, L. (2000). Seeing through the Seventies. Essays on Feminism and Art. Amsterdam: G+B Arts International, 181-182.

28 Wolverton, T. (2002). Insugent Muse. Life and Art at the Woman's Building. San Francisco: City Lights, 61

29 Harding, S. (1988). Feminism and Methodology. Indianapolis: Indiana University Press.
} 
persona ha adquirido como resultado de la realidad social en la que ha vivido. Lo que yo llamo subjetividad es el complejo proceso por el cual cada ser humano se convierte en ser social y en un individuo único. El proceso abarca tanto el cuerpo como el alma, las emociones, el intelecto y las fantasías; comienza en la infancia y continúa durante toda la vida. Subjetividad no es lo mismo que identidad, que es cómo me sitúan o cómo me sitúo a mí misma ante el resto dentro del campo social. Mientras que la identidad es múltiple y consciente, la subjetividad es singular, única y sólo parcialmente consciente: hay cosas sobre mí que no conozco y puede que nunca sepa (...) Todo esto constituye mi realidad psíquica e influye o condiciona mi experiencia ${ }^{30}$.

En coincidencia con las lesbianas argentinas que comenzaban a reivindicar una voz propia dentro de los movimientos de mujeres, D’Amico comenzó a preguntarse si la experiencia de este colectivo debía reflejarse en imágenes en donde el deseo marcara esa diferencia. ¿Cómo representar el deseo lésbico? ¿Debe éste abrir a un lenguaje visual diferente? Y de ser así ¿ello generaría la subversión del imaginario heteronormativo? Fue así que este viraje en su investigación sobre las representaciones visuales femeninas se fue refinando aún más. Recordando la frase expresada por Monique Wittig, las lesbianas no son mujeres ${ }^{31}$, D'Amico se propuso pensar en el correlato icónico de aquel enunciado. En relación con lo señalado, en 1986 escribió para la revista estadounidense Women of Power:

Estas imágenes forman parte de una serie fotográfica de parejas femeninas, tema que prácticamente no ha sido abordado en la fotografía argentina. Las modelos no son profesionales, sino parejas en la vida real. Pienso que es la única manera de abordar el tema, para que no pierda ternura ni autenticidad. Una sola de las fotografías ha sido publicada en pequeño formato por una revista de fotografía, dadas las dificultades que tropezamos gracias a una moral hipócrita que permite violaciones, violencia y asesinatos en los medios pero no acepta la realidad de las minorías. Pienso que las minorías son sencillamente eso: minorías que forman parte de un todo y que hacen a la totalidad de la especie humana. No se conoce existencia humana sin diversidad y esa es precisamente su riqueza ${ }^{32}$.

En ese sentido, D’Amico tenía la certeza de que el deseo lésbico debía y podía constituir un imaginario visual que diera cuenta de las disidencias sexuales. Es por ello que no quiere modelos posando, ya que buscaba captar con su cámara su circulación genuina, y así exponer las diferencias históricas de las lesbianas: su principal objetivo fue dar cuenta de su existencia.

Indicábamos más arriba que la investigación de D'Amico sobre el cuerpo y el deseo lésbico, fue en paralelo con los reclamos por la igualdad de derechos y la visibilidad que dicho colectivo había iniciado por entonces. Si por un lado existía una aceptación

30 De Lauretis, T. (2011). La creación artística y la autotraducción. En X. Arakistain y L. Méndez. (Eds.), Producción artística y teorías feministas del arte: nuevos debates $I V$. Vitoria: Centro Cultural Montehermoso, 138-149.

31 Wittig, M. (2006). El pensamiento heterosexual y otros ensayos. Barcelona: Egales, 56-57

32 Alicia D'Amico (1986). Escrito para Women of Power (manuscrito inédito del Archivo Alicia D'Amico). 
formal y teórica del lesbianismo dentro de los feminismos locales, su inclusión de facto seguía siendo compleja, es decir, las lesbianas sufrían frecuentemente la discriminación e invisibilidad, dentro de las agrupaciones, por las feministas heterosexuales. En Lugar de Mujer, prácticamente no se habló de lesbianismo hasta 1984, cuando la poeta Hilda Rais manifestó el derecho a una voz propia. Así, en una larga carta señaló:

No ejerzamos la violencia entre nosotras perpetuando otra división impuesta, el enemigo es el mismo y nos oprime de diversas maneras. Nuestro trabajo es ser sujeto de nuestras vidas y luchar juntas hasta que ya no sea necesario enunciar una identidad en función de una preferencia sexual, hasta que ya no sea necesario el feminismo ${ }^{33}$.

Entre 1986 y 1989 se organizó en Lugar de Mujer el Grupo de Reflexión Lesbia$n a$, realizando talleres y publicando un boletín que llevó el nombre Codo a Codo. Si bien el silenciamiento hacia este colectivo se venía dando desde los grupos de concienciación de los años $70^{34}$, el legado de éstos había sido muy fuerte para las feministas de los 80 y había dejado en claro que la posibilidad de dar un nuevo sentido de sí y del mundo no pasaba por la acción solitaria sino por las relaciones con las otras. Ahora era el momento.

La Argentina contó con una pluralidad de posiciones que posibilitaron la convivencia entre lesbianas radicales ${ }^{35}$ y lesbianas feministas en trabajos conjuntos. En relación con ello, en 1988 aparecían por primera vez los Cuadernos de Existencia Lesbiana, publicación que reflejó la necesidad de este colectivo por comenzar a escribir una historia propia. Los mismos se editaron sin interrupción hasta 1996. Allí se tradujeron y publicaron diversos textos de Susan Sontag, Audre Lorde, Adrienne Rich, Kate Millet, Simone Weil, Charlotte Bunch, Mary Daly, Judy Grahn, entre otras autoras extranjeras. También dieron lugar a los testimonios de lesbianas argentinas y a la literatura de escritoras como María Moreno, Alejandra Pizarnik, Cecilia Vicuña. Ricamente ilustrados con collages de la artista Josefina Quesada y fotografías o caricaturas de tono feminista elegidas por Ilse Fusková, Adriana Carrasco y Claudina Marek, los Cuadernos de Existencia Lesbiana constituyeron un modo de mostrar la riqueza de miradas dentro del lesbianismo argentino.

Por aquellos años, el taller de escritura para mujeres, dictado en 1989 por la escritora y poeta Diana Bellessi, motivó a la conformación de un grupo de estudio y reflexión sobre las experiencias lesbianas. Esto se dio por primera vez en el mes de julio de 1990. Dichos encuentros fueron la semilla para la organización del grupo Las lunas y las otras, quienes como lesbianas feministas, gestionaron un espacio propio, entre 1995 y 1999 , organizaron jornadas y publicaron un periódico semestral -en formato tabloide, sólo sa-

33 Rais, H. (1996). Lesbianismo. Apuntes para una discusión feminista. Travesías. Temas del debate feminista contemporáneo. Octubre, 137-142.

34 Al respecto señala la poeta Hilda Rais: "Si en una mujer lesbiana el miedo al rechazo, el miedo al miedo de la otra, ya constituía quizás parte de la adaptación a una forma de vida cercenada, a las feministas que queríamos construir y ampliar el Movimiento se nos atragantaba una encrucijada. Éramos atacadas, descalificadas, desde la derecha, la izquierda y el centro con distintos y hasta opuestos argumentos. Sin embargo todos coincidían en una anatema: feminista-lesbiana.” Rais, H. (1996). Lesbianismo. Apuntes para una discusión feminista. Travesías. Temas del debate feminista contemporáneo. Octubre, 21-24.

35 Por lesbianas radicales entendemos a aquellas que buscaban la abolición del régimen político de la heterosexualidad, con una fuerte tendencia al separatismo, ya que deseaban mantenerse fuera de la esfera de la política heterosexual. 
lieron dos números- en el que participó Alicia D'Amico. Asimismo, ellas organizaron el Frente de Lesbianas de Buenos Aires, con el que desarrollaron actos de visibilidad.

Los años 90 fueron fundamentales en relación con la lucha por los derechos de los colectivos de lesbianas y gays, y en ese sentido, cabe recordar que en 1990 la Organización Mundial de la Salud decidió quitar a la homosexualidad de su lista de enfermedades mentales. Tras la despatologización, se hacía urgente pelear contra los diferentes tipos de discriminación. La Primer Marcha del Orgullo Gay-Lésbico se realizó en Buenos Aires el 2 de julio de 1992. Con el tiempo, otros colectivos de disidencias sexuales fueron sumándose a esta lucha.

En consecuencia, la posibilidad de representarse vino luego de la decisión de nombrarse, de reconocerse. Una voz propia generó la conformación de un imaginario visual que diera testimonio de otras formas deseantes. Sin embargo, no adherimos a la idea de la existencia de un único deseo lesbiano ni de una única forma de representarlo. Siguiendo a Judith Butler, empleamos lesbianismo para "hacer uso de una categoría que dé cuenta de lo que excluye." ${ }^{36}$ La representación del deseo lésbico es tan plural como lesbianas que lo representen.

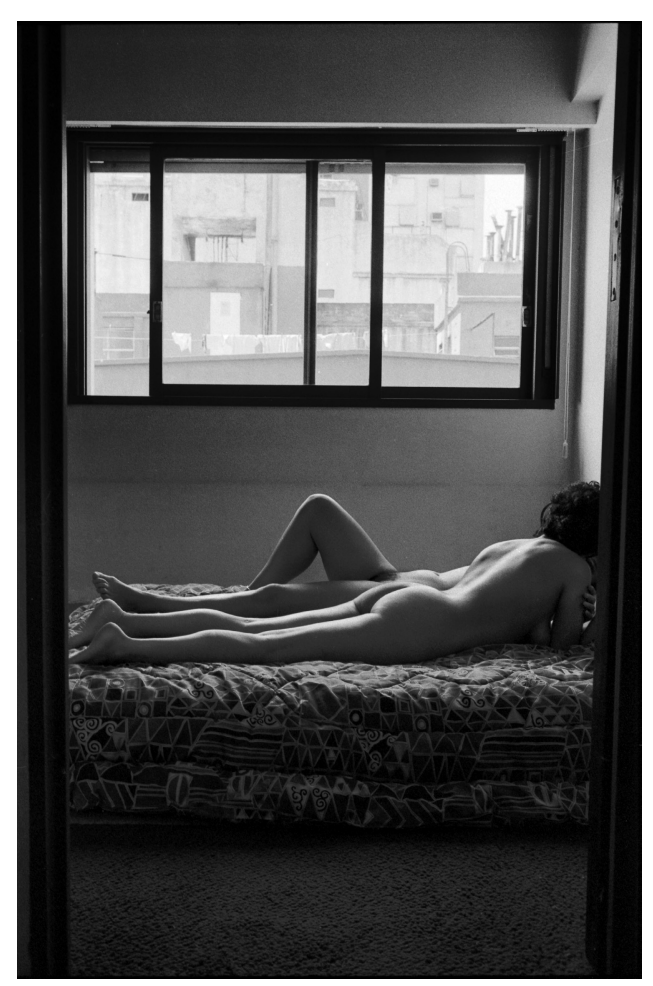

3. Alicia D'Amico (1933), La conversación (Liliana y Graciela), 20 de octubre de 1990. Copia de escaneos de negativo original, reproducción de contactos de negativo original, $35 \mathrm{~mm}$. Archivo Alicia D'Amico.

36 Señala Butler: "Más bien, a través del juego repetido de esta sexualidad el "yo" es reconstituido como un "yo" lesbiano, paradójicamente es la repetición de este juego la que también establece la inestabilidad de la categoría que la constituye.” Butler, J. (2000). Imitación e insubordinación de género. Revista de Occidente. $235,94$. 
En La conversación D'Amico, reflexionó sobre ello a través del sugerente desnudo de una pareja de mujeres, y al hacerlo, se detuvo en la voz y en la escucha de un diálogo sensual entre amantes. Aunque ingresamos a la escena por un gran ventanal que captura nuestra atención, inmediatamente, al bajar nuestra mirada, nos detenemos en los cuerpos de esas mujeres que se encuentran murmurándose al oído. El recorrido visual que describe esa escena íntima marca diferencias: quizás éste sea más elíptico y menos evidente que las imágenes de amantes lesbianas construidas para/por el deseo heterosexual masculino. En equilibrada composición, la ventana nos atrae con su luz para conducirnos hacia unos cuerpos que sutilmente se extienden sobre la cama. El título de la obra guía nuestra imaginación.

Similar situación se da en Pareja VII, quizás acentuando aún más la ambigüedad sexual de quienes se abrazan. No todo es tan evidente como las imágenes que acostumbramos ver. De esta manera, D'Amico puso de manifiesto que la falta de obviedad en las relaciones lésbicas no significaban su inexistencia. El lenguaje fotográfico salía en su ayuda. Así explicaba:

El enorme atractivo de la fotografía es su ambigüedad. Ambigüedad por ser una verdadera impostura de los seres y las cosas, ambigüedad por su lectura: deviene interesante cuando tiene varias interpretaciones. De cuasi perversa, salta sin esfuerzo a la inocencia ${ }^{37}$.

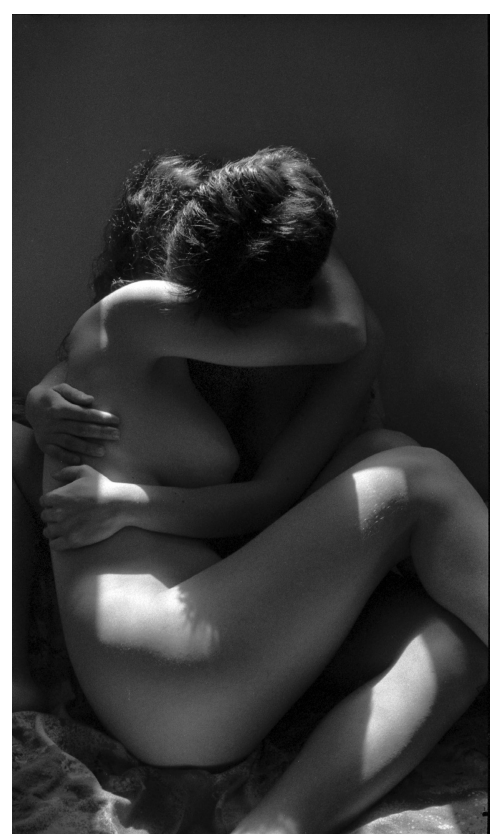

4. Alicia D’Amico (1933), Pareja VII (Vivi y Karin), septiembre de 1994.

Copia de escaneos de negativo original, reproducción de contactos de negativo original, $35 \mathrm{~mm}$. Archivo Alicia D'Amico.

37 D’Amico, A. (1999), texto sin título. [manuscrito inédito del Archivo Alicia D'Amico]. 
La fotografía, para D’Amico, era un medio como ningún otro a la hora de capturar lo escurridizo del deseo y la inestabilidad de la identidad. El desnudo brindaba un territorio a explorar que había sido poco usual, cuando no ignorado, por la fotografía argentina. Sin anécdotas narrativas que acompañaran a las parejas, ni objetos que interfirieran entre los cuerpos y el espacio, los gestos nos sumergían en un mundo de gráciles insinuaciones, en donde lo no dicho directamente desvelaba un universo.

Si bien ella se había destacado en la realización de importantes retratos desnudos a reconocidos músicos o escritores como ser Gato Barbieri o Severo Sarduy, en 1991 confesaba que el desnudo femenino no había estado dentro de sus primeros intereses dado que:

Durante mucho tiempo no quise tomar desnudos femeninos; la utilización del cuerpo femenino como objeto erótico en la mayoría de los medios y en cierta fotografía me molesta. El desnudo masculino era un tema mucho menos transitado en nuestra fotografía hasta ese momento. Los desnudos femeninos fueron apareciendo en un suave transcurrir y el objetivo no era estético ni formal; era ideológico ${ }^{38}$.

Sin embargo, el recorrido que la lleva desde la mujer verdad a dar cuenta de la experiencia entre lesbianas fue complejo y exigió de D’Amico no sólo un interés personal sino político. El taller Dar el cuerpo o dar la cara, fue presentado por primera vez en la casa de Las lunas y las otras, en 1994, e implicó un desafío para la fotógrafa ya que le mostró lo complejo que era hablar entre parejas lesbianas. Así indicaba:

Si bien hubo talleres con el tema de Autorretrato, Cambio, Violencia, Paz, El desnudo y los velos, era la primera vez que abordaba el tema de pareja de mujeres y no resultó fácil: una sola pareja entre cinco participantes, que finalmente sólo ofreció sus manos para las fotografías. Quizás esté bien que haya sido así; al fin de cuentas, el taller reflejó elocuentemente las trabas, los impedimentos y los condicionamientos exteriores e interiores de las parejas de mujeres para exponerse.

La exposición aludía al requerimiento de D'Amico de que las integrantes de los talleres firmaran su consentimiento para que algunas de las fotos, que las participantes seleccionaban, fueran expuestas y/o publicadas. De esa manera, las imágenes saldrían de una circulación privada e ingresarían en el espacio institucional, donde potenciarían su carga cuestionadora, subversiva, al visibilizar representaciones de mujeres otras. Esto sucedió cuando llevó a cabo su exposición Antológica, en el Centro Cultural Borges de la ciudad de Buenos Aires, poco antes de morir, en 2000. Allí exhibió una selección de piezas del taller El desnudo y los velos.

En el IV Encuentro de Lesbianas Feministas de América Latina y el Caribe, realizado en Mar del Plata, Argentina, en 1995, volvió a proponer Dar el cuerpo o dar la cara. El título implicaba una decisión política: salir del armario y asumirse tal como se es. En ese sentido las preguntas realizadas por Judith Butler en aquellos años -nos referimos a su conferencia Imitation and Gender Insubordination, dictada en 1989

38 D’Amico, A. (1991). El desnudo. Fotomundo, 284, 70-71. 
en el marco de la Conference on Homosexuality de la Universidad de Yale- se relacionaban con los límites de la visibilidad. Así decía:

¿Basta la visibilidad de la homosexualidad como estrategia política o es sólo el comienzo de una intervención estratégica que reclame por una transformación de la política? (...) No es este un llamamiento para volver al silencio o a la invisibilidad, sino más bien para usar una categoría que puede ser cuestionada, teniendo en cuenta lo que excluye. Es evidente que cualquier consolidación requiere algún conjunto de diferenciaciones y exclusiones. ¿Pero cuáles deben ser privilegiadas? El signo de identidad que utilizo tiene sus propósitos, pero no hay forma de predecir o controlar los usos políticos al que este signo será sometido en el futuro ${ }^{39}$.

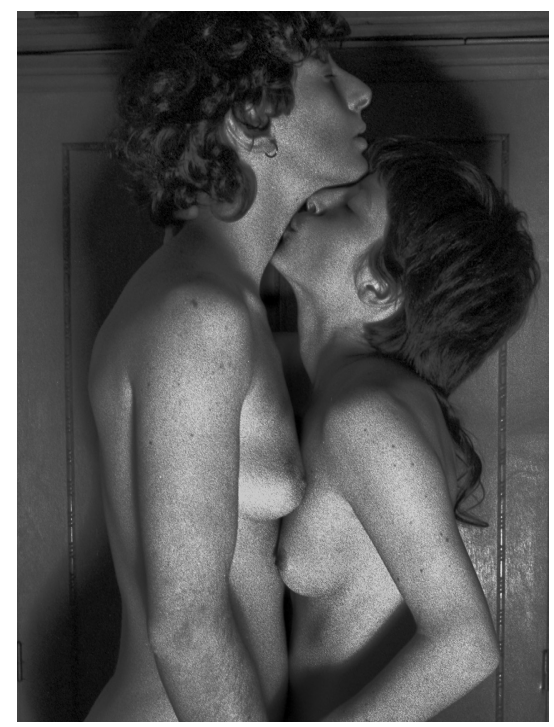

5. Alicia D'Amico, Dar el cuerpo o dar la cara, taller dictado en el IV Encuentro de Lesbianas Feministas de América Latina y el Caribe 1995.

Copia de escaneos de negativo original, reproducción de contactos de negativo original, $35 \mathrm{~mm}$. Archivo Alicia D’Amico.

Teniendo en cuenta lo fotografiado, D'Amico era consciente de la imposibilidad de controlar los usos políticos de sus obras, sin embargo, apostaba por la estrategia de la visibilidad como resistencia. Si definir la identidad lesbiana era una tarea absurda, fotografiar la pluralidad lésbica no lo era. En ello consistió lo radical de su propuesta. La fotografía no estaba para decir qué se era, sino que desde su ambigüedad y sutilezas, era una herramienta para mostrar aquello que no había sido nombrado, que no había sido explícitamente excluido porque no estaba dentro de lo pensable. Siguiendo a Butler: "Ser prohibido explícitamente implica ocupar un sitio discursivo desde el cual se puede articular un discurso de oposición, ser implícitamente proscripto, implica no calificar como un objeto de prohibición." ${ }^{40}$

39 Butler, J. (2000). Imitación e insubordinación de género. Revista de Occidente. 235, 95-96.

40 Butler, J. (2000). Imitación e insubordinación de género. Revista de Occidente. 235, 97. 
Aquello sin nombre, lo prácticamente inexistente en el discurso iconográfico del arte, o en el discurso visual de la fotografía, e incluso, en las construcciones canónicas de las escrituras de la historia del arte, era versátil, escurridizo, variable. D’Amico, con su cámara fotográfica, buscó atraparlo.

\section{Conclusiones}

La fotógrafa Alicia D'Amico desarrolló durante los años 80 y 90 del siglo XX, una investigación sin precedentes en el campo de la fotografía argentina, a la que denominó Creación de la propia imagen. A partir de su militancia dentro de las agrupaciones feministas de los años 70 , en donde circulaban materiales críticos con el sistema del patriarcado, cuestionó las representaciones visuales de las mujeres en los mass-media: reducidas a objetos para el placer masculino heterosexual, éstas conformaban un patrón de lo femenino opresivo, con el que el género debía identificarse.

Por medio del concepto mujer nueva, enunciado dentro de los grupos feministas, D'Amico reflexionó sobre la creación de representaciones que se detuvieran en los modos en que las mujeres se autopercibían. Entendió a la fotografía como una herramienta política cuestionadora de las imágenes femeninas circulantes. A través del género del retrato reflejó a la mujer verdad, idea con la que refiere a todas aquellas imágenes que mostraban a las mujeres tal como ellas se autopercibían. Para alcanzar estas representaciones, las mujeres debían participar de talleres organizados por D'Amico, y en algunas ocasiones, la fotógrafa fue acompañada por las psicólogas Graciela Sikos y Liliana Mizrahi, con quienes diseñó una metodología de trabajo que se nutrió de los grupos de concienciación feministas y de técnicas tomadas de la psicología, el psicodrama y el teatro. A través de esta modalidad, la fotógrafa exploró el lenguaje fotográfico, expandiendo y ampliando sus límites a la hora de registrar aquellos elementos personales que iban sugiriendo identidades y deseos, entendidos éstos en su inestabilidad y variabilidad. Así surgió una serie dedicada a bucear en el amor entre mujeres y el deseo lésbico.

Su investigación, dada su precocidad, se dio en coincidencia con las luchas por los derechos de lesbianas y gays, tanto a nivel nacional como internacional.

La radicalidad de la propuesta fotográfica de D'Amico la sitúa como una artista que llevó más allá de sus límites al género del desnudo fotográfico reflexionando a través de éste sobre las identidades sexo genéricas e implicándolo políticamente en la visibilidad del colectivo lésbico.

La fotografía fue su lengua política. 